\title{
Induction and maintenance of an experimental model of severe cardiomyopathy with a novel protocol of rapid ventricular pacing
}

\author{
Masami Takagaki, MD, PhDa \\ Patrick M. McCarthy, MDa,b \\ Tomotsugu Tabata, MD, PhDc \\ Ray Dessoffy, AAS ${ }^{a}$ \\ Lisa A. Cardon, RDCSc \\ Jason Connor, MS ${ }^{\mathrm{d}}$ \\ Yoshie Ochiai, MDa \\ James D. Thomas, MDC \\ Gary S. Francis, MDC \\ James B. Young, MDC \\ Kiyotaka Fukamachi, MD, PhDa
}

From the Department of Biomedical Engineering, ${ }^{a}$ Lerner Research Institute, the Departments of Thoracic and Cardiovascular Surgery, ${ }^{\mathrm{b}}$ and Cardiology, ${ }^{\mathrm{c}}$ George M. and Linda H. Kaufman Center for Heart Failure, and the Department of Biostatistics and Epidemiology, ${ }^{\mathrm{d}}$ The Cleveland Clinic Foundation, Cleveland, Ohio.

This study was funded by The Kaufman Center for Heart Failure and Myocor, Inc (Maple Grove, Minn).

Received for publication March 9, 2001; revisions requested April 30, 2001; revisions received June 20, 2001; accepted for publication June 26, 2001

Address for reprints: Patrick M. McCarthy, MD, Department of Thoracic and Cardiovascular Surgery/F25, The Cleveland Clinic Foundation, 9500 Euclid Ave, Cleveland, OH 44195 (E-mail: mccartp@ccf.org).

J Thorac Cardiovasc Surg 2002;123:544-9

Copyright (c) 2002 by The American Association for Thoracic Surgery

0022-5223/2002 $\$ 35.00+0 \quad \mathbf{1 2 / 1 / 1 1 8 2 7 6}$

doi:10.1067/mtc.2002.118276
Objective: An animal model of chronic severe heart failure is needed to evaluate new mechanical devices, surgical procedures, and medical therapies. The purpose of this study was to evaluate a unique new model of severe heart failure developed by means of a novel protocol of rapid ventricular pacing.

Methods: Heart failure was induced in 8 mongrel dogs by means of rapid ventricular pacing ( 230 beats/min) for 4 weeks. After a sham operation, maintenance pacing at a reduced rate (190 beats/min) was continued for another 4 weeks.

Results: Left ventricular systolic function was significantly reduced at week 4 and remained low at week 8 , including the slope of the end-systolic pressure-volume relationship ( $2.4 \pm 1.0$ vs $0.7 \pm 0.2$ vs $0.8 \pm 0.3 \mathrm{~mm} \mathrm{Hg} / \mathrm{mL}$ [baseline vs week 4 vs week 8 , respectively]), ejection fraction $(63 \% \pm 5 \%$ vs $28 \% \pm 7 \%$ vs $33 \% \pm 5 \%)$, and cardiac output ( $3.1 \pm 0.7$ vs $2.0 \pm 0.3$ vs $2.2 \pm 0.7 \mathrm{~L} / \mathrm{min})$. Significant ventricular remodeling changes took place with increased ventricular volumes and circumferential wall stress, which were stable between weeks 4 and 8 . Serum catecholamine and atrial natriuretic polypeptide levels also increased from baseline but stabilized between weeks 4 and 8 . The end-diastolic pressure-volume relationship also showed stable diastolic function between weeks 4 and 8 .

Conclusions: Induction pacing at 230 beats/min readily created severe heart failure in all animals, and a new technique of maintenance pacing provided a consistent model of severe heart failure. This model can be used to study a variety of new interventions for heart failure.

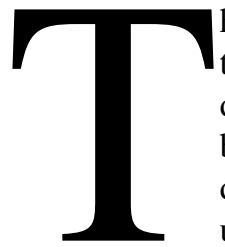

he epidemic of heart failure has led to the introduction of many new therapies that work through a variety of mechanisms. However, it is difficult to evaluate the long-term efficacy of these interventions because of the lack of a suitable model of stable chronic dilated cardiomyopathy $(\mathrm{DCM})$. The rapid-pacing heart-failure model has been used to simulate DCM. ${ }^{1-6}$ However, after cessation of rapid ventricular pacing, heart function quickly recovers. ${ }^{5,6}$ Modified pacing protocols have been introduced ${ }^{7,8}$ to try to produce chronic DCM. However, 4 weeks after cessation of pacing, cardiac filling pressures and diastolic function returned to normal, despite left ventricular (LV) systolic dysfunction. ${ }^{7}$ In another report with a long induction period of pacing, ${ }^{8} 8$ to 22 weeks after cessation of pacing, LV end-diastolic pressure (LVEDP) returned to normal, and there was significantly improved 
diastolic function. Therefore, even with these modified protocols designed to produce prolonged cardiac dysfunction, it would be very difficult to determine whether an intervention led to changes or whether the changes were due to recovery after pacing cessation.

We hypothesized that after induction pacing with rapid ventricular pacing (230 beats/min), chronic maintenance pacing at a reduced rate (190 beats/min) would maintain a stable level of severe cardiomyopathy similar to that of patients with late-stage DCM. The purpose of this study was to evaluate this unique model of chronic severe cardiomyopathy by using numerous assessments, including hemodynamic monitoring, 2-dimensional (2D) and 3dimensional (3D) echocardiography, pressure-volume loop analyses, pathologic examination, LV mass and wall-stress measurements, and neurohormone and serum catecholamine measurements.

\section{Materials and Methods}

\section{Animal Preparation and Surgical Procedures}

All animals received humane care in compliance with the "Guide for the Care and Use of Laboratory Animals" prepared by the Institute of Laboratory Animal Resources, National Research Council, and published by the National Academy Press (revised 1996). A total of 8 mongrel dogs (body weight, $26.6 \pm 1.2 \mathrm{~kg}$ ) were anesthetized with intravenous thiopental $(15 \mathrm{mg} / \mathrm{kg})$ and isoflurane $(0.5 \%-2.5 \%)$. A conductance catheter with 2 Millar pressure sensors (model SPC-562; Millar Instruments, Inc, Houston, Tex) was inserted into the left ventricle. A thermistortipped balloon catheter was inserted into the pulmonary artery. An inferior vena cava occlusion catheter (SciMed Owens balloon dilatation catheter; SciMed Life Systems, Inc, Maple Grove, Minn) was inserted to obtain the LV pressure-volume loops under various preloads. All hemodynamic data were recorded digitally during steady state and inferior vena caval occlusion at a sample rate of $200 \mathrm{~Hz}$ with the PowerLab (AD Instruments Inc, Mountain View, Calif) data-acquisition system as baseline values. Cardiac output was measured by using the thermodilution method. Stroke volume was calculated from cardiac output and heart rate (HR). A bipolar, screw-in, transvenous pacing lead (Medtronic 4068; Medtronic Inc, Minneapolis, Minn) was inserted into the right ventricular apex and attached to a programmable pulse generator (Medtronic 8086; Medtronic Inc) placed into the cervical pocket. Angiography was performed for $\mathrm{LV}$ volume calculation.

Rapid ventricular pacing ( 230 beats $/ \mathrm{min}$ ) was started 2 days or more after the operation. Before pacing and on the 27 th day of pacing, 2D transthoracic echocardiography (TTE) studies were performed with the animal awake and the pacemaker off. After 28 days of pacing at 230 beats/min, the animal was anesthetized in the same way as in the previous study with the pacemaker off. The hemodynamics were recorded as week 4 values in the same fashion as for baseline values. A 3D TTE study with a matrix phasedarray volumetric 3D imaging system (System V3.01; Volumetrics Medical Imaging, Durham, NC) was performed for the calibration of conductance LV volumes. A median sternotomy was performed, and the chest was opened. We waited for 45 minutes, sim- ulating the time needed for cardiac interventions, and closed the chest. Maintenance pacing at 190 beats/min was started on the third postoperative day. Each animal was given furosemide (40 $\mathrm{mg} / \mathrm{d}$ ) postoperatively and placed under careful observation for signs or symptoms of congestive heart failure for 4 weeks. Followup 2D TTE studies were performed once a week.

On the 28th postoperative day, the animal was anesthetized in the same way as for previous studies. The hemodynamics were recorded as week 8 values in the same fashion as for baseline values. A 3D TTE study was performed. The animal was then killed. The heart was harvested to measure the LV weight after trimming off the right ventricular free wall and the atria ${ }^{7}$ and stored in $10 \%$ formalin solution.

Additional studies were performed with 4 mongrel dogs (body weight, $26.1 \pm 0.4 \mathrm{~kg}$ ) in which we acquired blood samples at baseline and weeks $4,5,6,7$, and 8 for serum atrial natriuretic polypeptide (ANP) and total catecholamine (norepinephrine, epinephrine, and dopamine) measurements to better understand changes in the maintenance period. The experimental protocol was identical to that of our original 8 animals, except no hemodynamic or echocardiographic data were obtained.

\section{Hemodynamic Data Analysis}

Data analysis was performed with a custom-made visual basic program on Excel software (Excel 97 SR-1; Microsoft Corporation, Redmond, Wash). The maximum and minimum rates

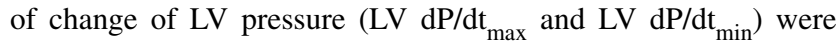
determined as the first derivative of the LV pressure (LVP). The time constant of isovolemic LVP decay $(\tau)$ was calculated by nonlinear regression. ${ }^{9}$

\section{Pressure-Volume Loops}

In 7 animals conductance volume data were acquired. LV volumes measured with the conductance catheter were calibrated to a 3D TTE or LV angiogram by a 2-point calibration on the basis of matching end-diastolic $\left(\mathrm{V}_{\mathrm{ED}}\right)$ and end-systolic $\left(\mathrm{V}_{\mathrm{ES}}\right)$ volumes. ${ }^{10}$ The volume from angiography was calculated by using the area-length method. ${ }^{11}$ The LV pressure-volume loops under various preloads were obtained by occluding the inferior vena cava. By connecting the upper left corners of the pressure-volume loops with an iterative linear regression method, we obtained the slope $\left(\mathrm{E}_{\max }\right)$ of the end-systolic pressurevolume relationship (ESPVR). The $\mathrm{E}_{\max }$ is known to be a loadindependent index of LV contractility. ${ }^{12,13} \mathrm{We}$ also evaluated the slopes of the $\mathrm{LV} \mathrm{dP/dt} t_{\max }-\mathrm{V}_{\mathrm{ED}}\left(\mathrm{dE} / \mathrm{dt}\right.$ ) and stroke work- $\mathrm{V}_{\mathrm{ED}}$ (preload recruitable stroke work) relationships, which are known to be loadindependent indices of LV contractility. ${ }^{14}$

The total energy generated by the left ventricle is approximated as the pressure-volume area, which is circumscribed by the ESPVR, end-diastolic pressure-volume relationship (EDPVR), and the systolic trajectory of the pressure-volume loop. The area inside the pressure-volume loop expresses external work. The ratio of external work/pressure-volume area reflects the mechanical efficiency of the ventricle. ${ }^{15}$

LV compliance, or diastolic property, was assessed by means of the EDPVR during inferior vena caval occlusion. LVEDP and LV volumes were fitted to the following exponential equation:

$$
\text { LVEDP }=\alpha \times \mathrm{e}^{\beta \times \mathrm{VED}}
$$


TABLE 1. Basic hemodynamics and echocardiographyderived parameters $(\mathbf{n}=\mathbf{8})$

\begin{tabular}{|c|c|c|c|}
\hline Condition & Baseline & Week 4 & Week 8 \\
\hline 0 (L/min) & $3.1 \pm 0.7$ & $2.0 \pm 0.3^{*}$ & $2.2 \pm 0.7^{*}$ \\
\hline HR (beats/min) & $125 \pm 10$ & $115 \pm 19$ & $140 \pm 16^{*} \dagger$ \\
\hline SV (mL) & $25 \pm 5$ & $18 \pm 4^{*}$ & $15 \pm 4^{*}$ \\
\hline ystolic LVP (mm Hg) & $135 \pm 26$ & $107 \pm 14^{*}$ & $105 \pm 21^{*}$ \\
\hline $\operatorname{LVEDP}(\mathrm{mm} \mathrm{Hg})$ & $7 \pm 2$ & $29 \pm 10^{*}$ & $21 \pm 12^{*} \dagger$ \\
\hline $\mathrm{VdP} / \mathrm{dt}_{\max }(\mathrm{mm} \mathrm{Hg} / \mathrm{s})$ & $2135 \pm 765$ & $1114 \pm 243^{*}$ & $1204 \pm 374^{*}$ \\
\hline $\mathrm{LVdP} / \mathrm{dt}_{\min }(\mathrm{mm} \mathrm{Hg} / \mathrm{s})$ & $-3013 \pm 1006$ & $-1178 \pm 261^{*}$ & $-1558 \pm 388^{*} \dagger$ \\
\hline$\tau(\mathrm{ms})$ & $33.1 \pm 3.8$ & $63.2 \pm 7.8^{*}$ & $38.7 \pm 8.4 \dagger$ \\
\hline Mean AoP (mm Hg) & $124 \pm 20$ & $95 \pm 10^{*}$ & $93 \pm 21^{*}$ \\
\hline SVR (dynes $\left.\cdot \mathrm{s} \cdot \mathrm{m}^{-5}\right) \ddagger$ & $3177 \pm 510$ & $3506 \pm 478$ & $3331 \pm 880$ \\
\hline Mean CVP (mm Hg) & $3 \pm 3$ & $7 \pm 4$ & $6 \pm 4^{*}$ \\
\hline Mean PCWP (mm Hg) & $6 \pm 2$ & $22 \pm 12^{*}$ & $16 \pm 11^{*}$ \\
\hline Mean PAP $(\mathrm{mm} \mathrm{Hg})$ & $13 \pm 2$ & $28 \pm 13^{*}$ & $22 \pm 12 \dagger$ \\
\hline PVR (dynes $\left.\cdot s \cdot m^{-5}\right) \ddagger$ & $178 \pm 47$ & $263 \pm 99 *$ & $231 \pm 127$ \\
\hline$V_{E D}(m L)$ & $79.2 \pm 8.7$ & $119.9 \pm 18.4^{*}$ & $114.4 \pm 26.5^{*}$ \\
\hline$V_{E S}(m L)$ & $29.3 \pm 4.4$ & $86.7 \pm 19.6^{*}$ & $76.1 \pm 18.3^{*}$ \\
\hline $\mathrm{EF}(\%)$ & $62.9 \pm 5.2$ & $28.4 \pm 7.3^{*}$ & $33.4 \pm 4.8^{*}$ \\
\hline MR (grade $0-4+$ ) & $0.1 \pm 0.2$ & $1.4 \pm 0.9^{*}$ & $1.3 \pm 1.1^{*}$ \\
\hline TR (grade $0-4+$ ) & $0.3 \pm 0.3$ & $1.9 \pm 0.8^{*}$ & $1.8 \pm 1.2^{*}$ \\
\hline ESWS $\left(10^{3} \cdot\right.$ dynes $\left.\cdot \mathrm{cm}^{-2}\right)$ & $230 \pm 44$ & $365 \pm 46^{*}$ & $337 \pm 79^{*}$ \\
\hline EDWS $\left(10^{3} \cdot\right.$ dynes $\left.\cdot \mathrm{cm}^{-2}\right)$ & $24 \pm 6$ & $123 \pm 49^{*}$ & $85 \pm 55^{*} \dagger$ \\
\hline LV mass $(\mathrm{mL})$ & $100 \pm 15$ & $106 \pm 20$ & $112 \pm 12$ \\
\hline
\end{tabular}

$A o P$, Aortic pressure; $C O$, cardiac output; $C V P$, central venous pressure; $E D W S$, end-diastolic wall stress; $E F$, ejection fraction; $E S W S$, end-systolic wall stress; $H R$, heart rate; $L V d P / d t_{\text {max }}$ maximum rate of change of LVP; $L V d P / d t_{\text {min }^{\prime}}$ minimum rate of change of LVP; $L V E D P$, left ventricular enddiastolic pressure; $M R$, mitral regurgitation; $P A P$, pulmonary arterial pressure; $P C W P$, pulmonary capillary wedge pressure; $P V R$, pulmonary vascular resistance; $S V$, stroke volume calculated from cardiac output and heart rate; $S V R$, systemic vascular resistance; $\tau$, time constant of isovolemic LVP decay; $T R$, tricuspid regurgitation; $V_{E D^{\prime}}$ end-diastolic volume; $V_{E S^{\prime}}$ end-systolic volume.

${ }^{*} P<.05$ compared with baseline.

$\dagger P<.05$ compared with week 4.

$\ddagger S V R$ and PVR were calculated as follows: (mean AoP - CVP)/CO $\times 80$ and (mean PAP - PCWP) $/ \mathrm{CO} \times 80$, respectively.

in each animal. ${ }^{16}$ We arbitrarily entered LVEDP values of 5, 10, 15 , and $20 \mathrm{~mm} \mathrm{Hg}$ in this equation and calculated corresponding $\mathrm{V}_{\mathrm{ED}}$. These $\mathrm{V}_{\mathrm{ED}}$ values were averaged and used to reconstruct the EDPVR at each data point. One animal was excluded from this analysis because the quality of data was not good enough to evaluate EDPVR.

\section{Echocardiographic Parameters}

End-diastolic and end-systolic cross-sectional areas (in square centimeters) in the short-axis view, both at the mitral anulus level $\left(\mathrm{MA}_{\mathrm{ED}}\right.$ and $\left.\mathrm{MA}_{\mathrm{ES}}\right)$ and at the midpapillary level $\left(\mathrm{PA}_{\mathrm{ED}}\right.$ and $\left.\mathrm{PA} \mathrm{ES}\right)$, and $\mathrm{LV}$ length (in centimeters), both end diastolic $\left(\mathrm{L}_{\mathrm{ED}}\right)$ and end systolic $\left(\mathrm{L}_{\mathrm{ES}}\right)$, in the long-axis view were measured. $\mathrm{V}_{\mathrm{ED}}$ (in milliliters), $\mathrm{V}_{\mathrm{ES}}$ (in milliliters), and ejection fraction (\%) were calculated with the equations shown below ${ }^{17}$ :

$$
\begin{gathered}
\mathrm{V}_{\mathrm{ED}}(\mathrm{mL})= \\
\mathrm{L}_{\mathrm{ED}} / 3 \times\left(\mathrm{MA}_{\mathrm{ED}}+\left[\mathrm{MA}_{\mathrm{ED}}+\mathrm{PA}_{\mathrm{ED}}\right] / 2+\mathrm{PA}_{\mathrm{ED}} / 3\right) ; \\
\mathrm{V}_{\mathrm{ES}}(\mathrm{mL})= \\
\mathrm{L}_{\mathrm{ES}} / 3 \times\left(\mathrm{MA}_{\mathrm{ES}}+\left[\mathrm{MA}_{\mathrm{ES}}+\mathrm{PA}_{\mathrm{ES}}\right] / 2+\mathrm{PA}_{\mathrm{ES}} / 3\right) ; \text { and } \\
\text { Ejection fraction }(\%)=\left(\mathrm{V}_{\mathrm{ED}}-\mathrm{V}_{\mathrm{ES}}\right) / \mathrm{V}_{\mathrm{ED}} \times 100 .
\end{gathered}
$$

From the Doppler echocardiogram, we evaluated the grade $(0-$ $4+$ ) of mitral regurgitation (MR) and tricuspid regurgitation (TR) from the 4-chamber view. ${ }^{18}$

Circumferential wall stress (WS) was calculated from the 2D TTE short-axis view at the papillary muscle level in combination with LVP by means of the following formula ${ }^{19}$ :

$$
\text { WS }\left(10^{3} \cdot \text { dynes } \cdot \mathrm{cm}^{-2}\right)=1.33 \times \mathrm{LVP} \times \mathrm{LVID} / 2 / \mathrm{PWT} \text {, }
$$

where LVID is LV internal diameter (in centimeters) and PWT is posterior wall thickness (in centimeters). Wall stress was calculated at both end-diastole (EDWS) and end-systole (ESWS).

LV mass was estimated by 2D TTE with the following formula ${ }^{20 .}$

$$
\begin{gathered}
\text { LV mass }(\mathrm{mL})= \\
\left(\pi[\mathrm{LVID} / 2+\mathrm{PWT}]^{2}-\pi[\mathrm{LVID} / 2]^{2}\right) \times \mathrm{L}_{\mathrm{ED}} .
\end{gathered}
$$

In addition, the actual LV mass was measured and normalized by body weight at autopsy (LV mass index [in grams per kilograms]). ${ }^{7}$

\section{Histologic and Biochemical Examination}

The LV tissue was dehydrated and embedded in paraffin. Serial sections were cut at a thickness of $5 \mu \mathrm{m}$ and stained with hematoxylin and eosin at American Histolabs (Gaithersburg, Md). All the histologic examinations were done by an experienced pathologist.

Blood for plasma ANP and catecholamine assay was collected in ethylenediamine tetraacetic acid and heparinized tubes, respectively, and immediately placed on ice. After centrifugation at 3500 revolutions per minute for 7 minutes, the plasma was decanted and stored at $-20^{\circ} \mathrm{C}$ until analysis. Plasma ANP was measured by means of specific radioimmunoassay (Mayo Medical Laboratories, Rochester, Minn). ${ }^{21}$ Plasma catecholamine concentrations were determined by high-performance liquid chromatography.

\section{Statistical Analysis}

All data were expressed as mean values \pm SD. The changes of all parameters from baseline to week 4 , baseline to week 8 , and week 4 to week 8 were analyzed with a paired $t$ test. No correction of $P$ values for multiple comparisons was made. Changes in parameters that have multiple data points (baseline and weeks 4, 5, 6, 7, and 8 ) were analyzed by repeated-measures analysis of variance for those during the maintenance period (weeks 4-8) and with paired $t$ tests for those between baseline and weeks 4 to 8 .

\section{Results}

The changes in basic hemodynamics are shown in Table 1. Cardiac output, stroke volume, systolic LVP, LVEDP, LV $\mathrm{dP} / \mathrm{dt}_{\max }, \mathrm{LV} \mathrm{dP/ \textrm {dt } _ { \text { min } }}$, mean aortic pressure, and pulmonary capillary wedge pressure were significantly worse at both weeks 4 and 8 compared with baseline values. Although most of the parameters were stable between weeks 4 and 8 , 


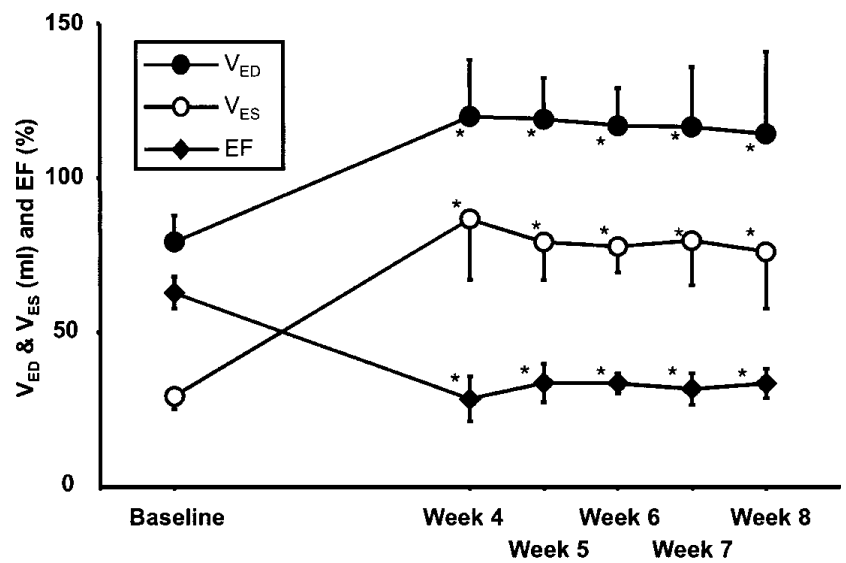

Figure 1. $v_{E D}, v_{E S}$, and ejection fraction (EF) from echocardiography $(\mathbf{n}=8)$. $V_{E D}$ significantly $(P=.0003)$ increased at week 4 compared with baseline values. $V_{E S}$ also significantly $(P=.0001)$ increased at week 4 compared with baseline values. Consequently, ejection fraction significantly $(P=.00000)$ decreased at week 4 . These changes were maintained at week 8 $(P=.005, P=.0001$, and $P=.000001$ vs baseline values, respectively; all $P=$ not significant vs week 4$)$. The changes of parameters between weeks 4 and 8 and from baseline to each week were analyzed with repeated-measures analysis of variance and a paired $\boldsymbol{t}$ test. Analysis of variance showed no significant changes in these echocardiographic parameters between weeks 4 and 8 . ${ }^{*} \boldsymbol{P}<.05$ compared with baseline values.

some changed. HR significantly increased at week 8 compared with baseline and week 4 values. LVEDP, LV $\mathrm{dP} / \mathrm{dt}_{\min }, \tau$, and mean pulmonary arterial pressure significantly decreased at week 8 compared with at week 4 .

The changes in echocardiography-derived data are shown in Table 1 and Figure $1 . \mathrm{V}_{\mathrm{ED}}$ and $\mathrm{V}_{\mathrm{ES}}$ significantly increased, which is typical of a remodeled failing heart, and ejection fraction significantly decreased at week 4 compared with baseline values. These changes were maintained and stable between weeks 4 and 8 . None of the animals showed evidence of MR or TR greater than trivial levels at baseline. At week 4, significant MR and TR developed compared with baseline values. Both of them remained at week 8 and were unchanged $(P=$ not significant) from week 4. ESWS and EDWS significantly increased at weeks 4 and 8 compared with baseline values. Although ESWS was stable between weeks 4 and $8(P=$ not significant $)$, EDWS significantly decreased at week 8 compared with at week 4 . LV mass increased continuously from baseline to week 8 and approached significance $(P=.06)$. In addition, $\mathrm{LV}$ mass index measured at autopsy was $5.36 \pm 0.70 \mathrm{~g} / \mathrm{kg}$, which was comparable with a previous report of canine paced heart failure. ${ }^{7}$

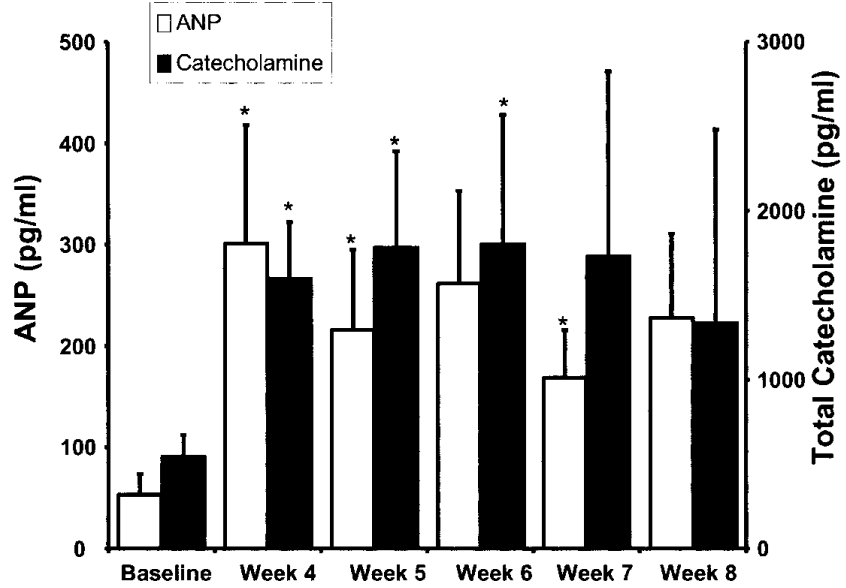

Figure 2. Plasma biochemical markers $(n=4)$. ANP and total catecholamine (norepinephrine, epinephrine, and dopamine) levels were significantly $(P<.05)$ increased at week $4(301 \pm 117$ and $1599 \pm 333 \mathrm{pg} / \mathrm{mL}$ ) compared with baseline levels (53 \pm 20 and 545 $\pm 128 \mathrm{pg} / \mathrm{mL}$ ) and remained elevated between weeks 4 and 8 . The changes of parameters between weeks 4 and 8 and from baseline to each week were analyzed with repeated-measures analysis of variance and a paired $t$ test. Analysis of variance showed no significant changes in these biochemical parameters between weeks 4 and 8 . ${ }^{*} \boldsymbol{P}<.05$ compared with baseline levels.

Parameters from pressure-volume analysis are shown in Table 2. $\mathrm{E}_{\max }(P=.004)$, preload recruitable stroke work $(P$ $=.03)$, and $\mathrm{dE} / \mathrm{dt}(P=.02)$ significantly decreased at week 4 compared with baseline values. These changes were maintained at week $8(P=.009, P=.02$, and $P=.03$ vs baseline values, respectively; all $P=$ not significant vs week 4 values). The volume axis intercept of ESPVR was $-15 \pm$ $19 \mathrm{~mL}$ at baseline, $-100 \pm 65 \mathrm{~mL}$ at week 4 , and $-90 \pm 70$ $\mathrm{mL}$ at week 8 . The volume axis intercept of the stroke work$\mathrm{V}_{\mathrm{ED}}$ relationship was $16 \pm 18 \mathrm{~mL}$ at baseline, $-18 \pm 59 \mathrm{~mL}$ at week 4 , and $-2 \pm 48 \mathrm{~mL}$ at week 8 . LV efficiency significantly decreased at week 4 ( $P=.01$ vs baseline values) and was stable at week $8(P=$ not significant vs week 4 values $)$. In addition, the evaluation of reconstructed EDPVR at LVEDP values of 5, 10, 15, and $20 \mathrm{~mm} \mathrm{Hg}$ revealed that all these points were not significantly different at week 8 compared with week 4 values ( $P=$ not significant).

Hypertrophy of cardiac myofibers, which is characterized by large, rounded, eosinophilic cells with a large and prominent basophilic nucleus, and interstitial edema were common in the myocardium of all animals. The apical side of the septum usually demonstrated the most marked hypertrophy.

Plasma ANP and total catecholamine levels were significantly increased at week 4 compared with baseline values and remained elevated and stable between weeks 4 and 8 , as 
TABLE 2. Results of pressure-volume loops analysis $(n=7)$

\begin{tabular}{lccc}
\hline Condition & Baseline & Week 4 & Week 8 \\
\hline $\mathrm{E}_{\max }(\mathrm{mm} \mathrm{Hg} / \mathrm{mL})$ & $2.4 \pm 1.0$ & $0.7 \pm 0.2^{*}$ & $0.8 \pm 0.3^{*}$ \\
$\mathrm{PRSW}(\mathrm{mm} \mathrm{Hg})$ & $49.5 \pm 28.3$ & $26.4 \pm 16.5^{*}$ & $19.2 \pm 5.5^{*}$ \\
$\mathrm{dE} / \mathrm{dt}\left(\mathrm{mm} \mathrm{Hg} \cdot \mathrm{s}^{-1} \cdot \mathrm{mL}^{-1}\right)$ & $19.4 \pm 11.6$ & $5.3 \pm 2.9^{*}$ & $7.0 \pm 3.7^{*}$ \\
$\mathrm{LV} \mathrm{efficiency}(\%)$ & $39 \pm 12$ & $23 \pm 9^{*}$ & $18 \pm 7^{*}$ \\
\hline
\end{tabular}

$E_{\text {max }}$ Slope of end-systolic pressure-volume relationship; $d E / d t$, slope of the $\mathrm{LV} \mathrm{dP} / \mathrm{dt}_{\max }-\mathrm{V}_{\mathrm{ED}}$ relationship; $\mathrm{LV} \mathrm{dP} / \mathrm{dt}_{\max }$ maximum rate of change of LV pressure; $P R S W$, Preload recruitable stroke work (slope of the stroke work- $V_{E D}$ relationship).

${ }^{*} P<.05$ compared with baseline.

shown in Figure 2. Analysis of variance showed no significant changes between weeks 4 and 8 .

\section{Discussion}

Consistent with previous investigations, we were able to use induction pacing to create severe LV dysfunction, and heart failure was manifested by changes in all parameters. Unlike previous studies, however, the maintenance pacing at 190 beats/min allowed a very stable model of severe cardiomyopathy to emerge. Measurements of pressure-volume loops, hemodynamics, echocardiography, LV mass and wall stress, pathologic examination, and plasma ANP and catecholamine levels all confirmed severe, persistent cardiomyopathy. The model was associated with structural changes consistent with LV remodeling, reduction in LV performance measured by means of load-independent methods, elevated levels of plasma ANP and catecholamines, and impaired hemodynamics. Furthermore, the dilated, poorly contracting hearts exhibited MR and TR at a level that is common in patients with DCM.

Although the majority of parameters were stable between weeks 4 and 8 , not all measurements remained stable. There was an increase in HR at week 8 compared with at week 4 , and LVEDP, LV dP/dt ${ }_{\text {min }}$, $\tau$, mean pulmonary arterial pressure, and EDWS significantly decreased at week 8 compared with week 4 values. These values, however, were still distinctly abnormal compared with baseline values. The use of furosemide between weeks 4 and 8 may have accounted for some of the decrease in cardiac filling pressures and led to the compensatory increase in HR to maintain cardiac output. Our prior studies ${ }^{22}$ indicated that maintaining animals at this level of heart failure without furosemide led to a high mortality caused by chronic volume overload with pleural effusions and ascites. Although the increased HR may have influenced the HR-dependent

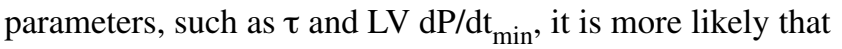
measures of active relaxation improved significantly from week 4. However, our observation that EDPVR did not change between weeks 4 and 8 implied that passive diastolic properties did not change in this model.
Other investigators have achieved a chronic model of heart failure through the use of coronary microsphere injections. ${ }^{23,24}$ The microsphere-damaged myocardium model exhibits extensive fibrosis and is more akin to ischemic cardiomyopathy than DCM. Also, unlike the microsphereinjection model, which may require multiple procedures and several months to induce heart failure, this pacinginduced heart-failure model can be initiated with a single operation, the pacemaker implantation.

Although previous models of pacing-induced heart failure demonstrated recovery of cardiac function after cessation of pacing, even with modified protocols, ${ }^{7,8}$ our model maintained a much more severe cardiomyopathy and therefore was clinically similar to patients with end-stage cardiomyopathy. In one earlier study, ${ }^{8}$ ejection fraction recovered from $25 \%$ to $45 \% 2$ weeks after the cessation of pacing, and LVEDP decreased from 15 to $5 \mathrm{~mm} \mathrm{Hg} 8$ weeks after cessation of pacing. In our model there was a persistently depressed myocardial performance.

Much attention is being directed to finding new therapies for heart failure. New surgical or device-based therapies that may be addressed by this model include the Myocor Myosplint, ${ }^{22}$ Acorn Cardiac Support Device, ${ }^{25}$ Cardioclasp, ${ }^{26}$ Batista procedure (partial left ventriculectomy), ${ }^{27}$ mitral valve repair for severe LV dysfunction, ${ }^{28}$ gene therapy, ${ }^{29}$ or cell therapy. ${ }^{30}$ Although the chronic microembolization model may be applicable to some of these innovations, a model more closely approximating idiopathic DCM would be useful.

\section{Study Limitation}

Although the majority of parameters were stable between weeks 4 and 8 , some cardiac filling pressures decreased. HR increased, perhaps associated with the furosemide administered to maintain the animals at clinically stable levels, allowing them to survive to study termination. MR in this model was evaluated with color Doppler scanning, and more quantitative evaluation, including assessment of proximal isovelocity surface area, would be more appropriate for further studies. Furthermore, because MR is an important component of DCM, another protocol to create more severe MR may be appropriate to assess interventions on the mitral valve. Although LV mass increased continuously from baseline to week 8, it did not reach statistical significance $(P=.06)$. Lack of hypertrophy in this model should be considered as a limitation. Because the volume axis intercept for ESPVR was much smaller after induction of heart failure, there might have been some problems with absolute values of volumes. However, this calibration method by matching $\mathrm{V}_{\mathrm{ES}}$ and $\mathrm{V}_{\mathrm{ED}}$ is the only theoretically reasonable method in the presence of $\mathrm{MR}$, unless we can measure the amount of MR precisely. Although it was impossible to validate this calibration in our data, the simi- 
lar changes in much simpler parameters, such as LV $\mathrm{dP} / \mathrm{dt}_{\max }$, support our conclusion of depressed contractility at weeks 4 and 8 . Finally, these studies were designed to terminate at week 8, and it is not yet known how much longer animals can be maintained in this late stage of heart failure.

\section{Conclusion}

Induction pacing at 230 beats/min over 4 weeks produced severe cardiomyopathy in all animals. Maintenance pacing at 190 beats/min maintained a stable level of severe cardiomyopathy similar to that of patients with end-stage idiopathic DCM. This model of persistent, severe cardiomyopathy should allow for the evaluation of new and existing therapies for heart failure.

We thank Dr George Ruth for his pathologic examinations and Mr Michael Kopcak for his excellent technical assistance in the experiments. We also thank Ms Christine Kassuba for editorial assistance in the preparation of this article.

\section{References}

1. Whipple GH, Sheffield LT, Woodman EG, Theophilis C, Friedman S. Reversible congestive heart failure due to chronic rapid stimulation of the normal heart. Proc N Engl Cardiovasc Soc. 1962;20:39-40.

2. Travill CM, Williams TD, Pate P, Song G, Chalmers J, Lightman SL, et al. Haemodynamic and neurohumoral response in heart failure produced by rapid ventricular pacing. Cardiovasc Res. 1992;26:783-90.

3. Armstrong PW, Stopps TP, Ford SE, de Bold AJ. Rapid ventricular pacing in the dog: pathophysiologic studies of heart failure. Circulation. 1986;74:1075-84.

4. Howard RJ, Moe GW, Armstrong PW. Sequential echocardiographicDoppler assessment of left ventricular remodelling and mitral regurgitation during evolving experimental heart failure. Cardiovasc Res. 1991:25:468-74.

5. Tomita M, Spinale FG, Crawford FA, Zile MR. Changes in left ventricular volume, mass, and function during the development and regression of supraventricular tachycardia-induced cardiomyopathy: disparity between recovery of systolic versus diastolic function. Circulation. 1991;83:635-44.

6. Spinale FG, Holzgrefe HH, Mukherjee R, Arthur SR, Child MJ, Powell JR, et al. LV and myocyte structure and function after early recovery from tachycardia-induced cardiomyopathy. Am J Physiol. 1995;268:H836-47.

7. Yamamoto K, Burnett JC Jr, Meyer LM, Sinclair L, Stevens TL, Redfield MM. Ventricular remodeling during development and recovery from modified tachycardia-induced cardiomyopathy model. Am J Physiol. 1996;271:R1529-34.

8. Patel HJ, Pilla JJ, Polidori DJ, Pusca SV, Plappert TA, Sutton MS, et al. Ten weeks of rapid ventricular pacing creates a long-term model of left ventricular dysfunction. J Thorac Cardiovasc Surg. 2000;119:834-41.

9. Weiss JL, Frederiksen JW, Weisfeldt ML. Hemodynamic determinants of the time-course of fall in canine left ventricular pressure. $J$ Clin Invest. 1976;58:751-60.

10. Kass DA, Wolff MR, Ting CT, Liu CP, Chang MS, Lawrence W, et al. Diastolic compliance of hypertrophied ventricle is not acutely altered by pharmacologic agents influencing active processes. Ann Intern Med. 1993;119:466-73.

11. Wynne J, Green LH, Mann T, Levin D, Grossman W. Estimation of left ventricular volumes in man from biplane cineangiograms filmed in oblique projections. Am J Cardiol. 1978;41:726-32.
12. Suga H, Sagawa K, Shoukas AA. Load independence of the instantaneous pressure-volume ratio of the canine left ventricle and effects of epinephrine and heart rate on the ratio. Circ Res. 1973;32:314-22.

13. Suga $\mathrm{H}$, Sagawa K. Instantaneous pressure-volume relationships and their ratio in the excised, supported canine left ventricle. Circ Res. 1974;35:117-26.

14. Little WC, Cheng CP, Mumma M, Igarashi Y, Vinten-Johansen J, Johnston WE. Comparison of measures of left ventricular contractile performance derived from pressure-volume loops in conscious dogs. Circulation. 1989;80:1378-87.

15. Suga H. Ventricular energetics. Physiol Rev. 1990;70:247-77.

16. Ratcliffe MB, Wallace AW, Salahieh A, Hong J, Ruch S, Hall TS. Ventricular volume, chamber stiffness, and function after anteroapical aneurysm plication in the sheep. J Thorac Cardiovasc Surg. 2000;119: $115-24$.

17. Stamm RB, Carabello BA, Mayers DL, Martin RP. Two-dimensional echocardiographic measurement of left ventricular ejection fraction: prospective analysis of what constitutes an adequate determination. Am Heart J. 1982;104:136-44.

18. Miyatake $\mathrm{K}$, Izumi $\mathrm{S}$, Okamoto $\mathrm{M}$, Kinoshita $\mathrm{N}$, Asonuma $\mathrm{H}$, Nakagawa $\mathrm{H}$, et al. Semiquantitative grading of severity of mitral regurgitation by real-time two-dimensional Doppler flow imaging technique. J Am Coll Cardiol. 1986;7:82-8.

19. Fujii AM, Gelpi RJ, Mirsky I, Vavter SF. Systolic and diastolic dysfunction during atrial pacing in conscious dogs with left ventricular hypertrophy. Circ Res. 1988;62:462-70.

20. Feneley MP, Gaynor JW, Maier GW, Gall SA Jr, Kisslo JA, Rankin JS. In vivo estimation of left ventricular wall volume in volume-overloaded canine hearts. Am J Physiol. 1988;255:H1399-404.

21. Burnett JC Jr, Kao PC, Hu DC, Heser DW, Heublein D, Granger JP, et al. Atrial natriuretic peptide elevation in congestive heart failure in the human. Science. 1986;231:1145-7.

22. McCarthy PM, Takagaki M, Ochiai Y, Young JB, Tabata T, Shiota T, et al. Device-based change in left ventricular shape: a new concept for the treatment of dilated cardiomyopathy. J Thorac Cardiovasc Surg. 2001;122:482-90.

23. Sabbah HN, Stein PD, Kono T, Gheorghiade M, Levine TB, Jafri S, et al. A canine model of chronic heart failure produced by multiple sequential coronary microembolizations. Am J Physiol. 1991;260: H1379-84.

24. Huang Y, Kawaguchi O, Zeng B, Carrington RAJ, Horam CJ, Yuasa $\mathrm{T}$, et al. A stable ovine congestive heart failure model: a suitable substrate for left ventricular assist device assessment. ASAIO J. 1997;43:M408-13.

25. Power JM, Raman J, Dornom A, Farish SJ, Burrell LM, Tonkin AM, et al. Passive ventricular constraint amends the course of heart failure: a study in an ovine model of dilated cardiomyopathy. Cardiovasc Res. 1999;44:549-55.

26. Shimizu J, Wang J, Yi GH, He K, Kashem MA, Crabbe DL, et al. Improved systolic performance by passive remodeling in experimental heart failure. Circulation. 2000;102:II-683.

27. McCarthy PM, Starling RC, Wong J, Scalia GM, Buda T, Vargo RL, et al. Early results with partial left ventriculectomy. $J$ Thorac Cardiovasc Surg. 1997;114:755-63.

28. Bolling SF, Pagani FD, Deeb GM, Bach DS. Intermediate-term outcome of mitral reconstruction in cardiomyopathy. $J$ Thorac Cardiovasc Surg. 1998;115:381-8.

29. Sabbah HN, Suzuki G, Mishima T, Sharov VG, Morita H, Nass O, et al. Intracoronary infusion of vascular endothelial growth factor (VEGF) improves left ventricular function in dogs with heart failure. Circulation. 2000;102:II-452.

30. Scorsin M, Hagege A, Vilquin JT, Fiszman M, Marotte F, Samuel JL, et al. Comparison of the effects of fetal cardiomyocyte and skeletal myoblast transplantation on postinfarction left ventricular function. $J$ Thorac Cardiovasc Surg. 2000;119:1169-75. 